\title{
Comparison of the Skin Lipid Layer in Acne Vulgaris Patients after Treatment with $50 \%$ Lactobionic Acid, Corundum Microdermabrasion and a Combination of Both Means
}

\author{
Beata Marczyk1, Paulina Mucha², Helena Rotsztejn ${ }^{1 *}$, Elzbieta Budzisz² \\ ${ }^{1}$ Department of Cosmetology and Esthetic Dermatology, Medical University of Lodz, Lodz, Poland \\ ${ }^{2}$ Department of Cosmetic Raw Material Chemistry, Medical University of Lodz, Lodz, Poland \\ Email: "helena.rotsztejn@umed.lodz.pl
}

Received 8 July 2016; accepted 15 August 2016; published 18 August 2016

Copyright (C) 2016 by authors and Scientific Research Publishing Inc.

This work is licensed under the Creative Commons Attribution International License (CC BY). http://creativecommons.org/licenses/by/4.0/

(c) (;) Open Access

\section{Abstract}

Background: The uses of lactobionic acid, corundum microdermabrasion, and a combined technique, are treatments supporting therapies for acne vulgaris and seborrhoea. Objectives: The work was conducted to determine the effects of the peeling with lactobionic acid, corundum microdermabrasion, and a combined technique of both means on sebum secretion in acne vulgaris patients. Methods: The peeling with $50 \%$ lactobionic acid, the corundum microdermabrasion, and the combined technique were applied to 45 female patients divided into three groups of fifteen people each. Every one treatment was given five times in two week intervals. The measurements of sebum secretion were done within the T- and U-zones using Sebumeter SM15 (Courage \& Khazaka, Germany). The last (sixth) measurement was performed two weeks after the last treatment. Results: Decrease in the level of sebum secretion was found during second or third measurement. Two weeks after the last treatment, the biggest decrease in the level of sebum secretion was observed in the patients treated with lactobionic acid, followed by those treated with the combined method. Conclusions: Treatments consisting of the peeling with lactobionic acid, corundum microdermabrasion, or the combined technique, brought significant decrease in the level of sebum secretion. The biggest decrease was observed in the patients treated with lactobionic acid, which being structurally similar to $\alpha$-hydroxyacids exerts exfoliating properties. The combined method was also effective, because of increased skin penetration of the active ingredients, resulting from the abrasion of stratum corneum during the corundum microdermabrasion. The corundum microdermabrasion alone was the least effective approach.

\footnotetext{
${ }^{*}$ Corresponding author.

How to cite this paper: Marczyk, B., Mucha, P., Rotsztejn, H. and Budzisz, E. (2016) Comparison of the Skin Lipid Layer in Acne Vulgaris Patients after Treatment with $50 \%$ Lactobionic Acid, Corundum Microdermabrasion and a Combination of Both Means. Journal of Cosmetics, Dermatological Sciences and Applications, 6, 156-166.

http://dx.doi.org/10.4236/jcdsa.2016.64020
} 


\section{Keywords}

\section{Lactobionic Acid, Corundum Microdermabrasion, A Combined Method, Sebumeter, Acne Vulgaris, Facial Seborrhoea}

\section{Introduction}

There are multiple and complex causes for acne vulgaris. The disease touches $75 \%-95 \%$ of the teenagers around the world. In $95 \%$ of cases, the skin changes are located on the face and other upper parts of the body (the chest and back) [1]. In a local treatment, different chemical peeling and mechanical abrasion procedures are recommended, often in combination with the other methods [2] [3]. Because of the chronic character and localization of the changes within much exposed parts of the body, the disease also brings severe psychological problems to the patients [4]. In the literature, one can find only limited data on sebumetric comparison of the skin lipid layer after treatment with lactobionic acid (LA) and corundum microdermabrasion. Both of them could have influence on the level of sebum secretion as LA is a hygroscopic substance with occlusive and exfoliating properties and corundum microdermabrasion removes the outer layers of epidermis and facilitates the penetration of skin by cosmetics' active ingredients.

Our work was conducted to determine the level of serum secretion on the face skin of acne vulgaris patients after the five-time treatment (the peeling with 50\% LA, corundum microdermabrasion, or a combined technique) executed in two-week intervals and, finally, two weeks after the last treatment.

\section{Methodology}

\subsection{Participants}

The patients suffered from acne of intensity between 0.25 and 2.0 (a low to medium grade according to Cunliffe's scale) [5]. The participants had facial skin of a I or III type (Fitzpatrick's classification) and were not treated over last three months. No other facial skin changes than acne and elevated sebum secretion were detected.

Statistical analysis of the age distribution in the treatment groups showed no statistically significant differences $(\mathrm{F}=0.12 ; \mathrm{p}>0.05)$ (Figure 1).

The study took twenty weeks, from January to April (to avoid the period of sun exposure). The study was approved by Bioethics Committee of the Medical University in Lodz (RNN/66/13/KE). Written informed consent of the participants and the guardians of the under-age subjects was obtained. Each patient was informed about transient adverse reactions associated with the procedures.

\subsection{Procedures}

The level of skin grease was measured on skin of forehead, left and right cheek, nose and chin using Sebumeter SM15 (Courage \& Khazaka, Germany) (Table 1). A special cassette with a pergamin ribbon was used to assess the level of skin sebum. Following the manufacturer recommendation, the ribbon was pressed against the skin with a force of $4 \mathrm{~N}$ for $30 \mathrm{~s}$, followed by photometric analysis using an MP15 photometer [6]-[8]. The mea-

Table 1. Age distribution analysis in the treatment groups (in years).

\begin{tabular}{cccccc}
\hline Treatment & $\begin{array}{c}\text { Number of } \\
\text { patients }\end{array}$ & $\begin{array}{c}\text { Lowest } \\
\text { age }\end{array}$ & Highest age & Average age & Standard deviation (SD) \\
\hline Lactobionic acid & 15 & 14.0 & 23.0 & 19.40 & \pm 2.85 \\
Lactobionic acid + corundum microdermabrasion & 15 & 15.0 & 23.0 & 19.27 & \pm 2.69 \\
Corundum microdermabrasion & 15 & 16.0 & 22.0 & 19.27 & \pm 2.15 \\
Total & 45 & 14.0 & 23.0 & 19.31 & \pm 2.52 \\
Statistical analysis & & & \multicolumn{2}{c}{ Variance Analysis Test F $=0.12 \mathrm{p}>0.05$} \\
\end{tabular}


Age of patients

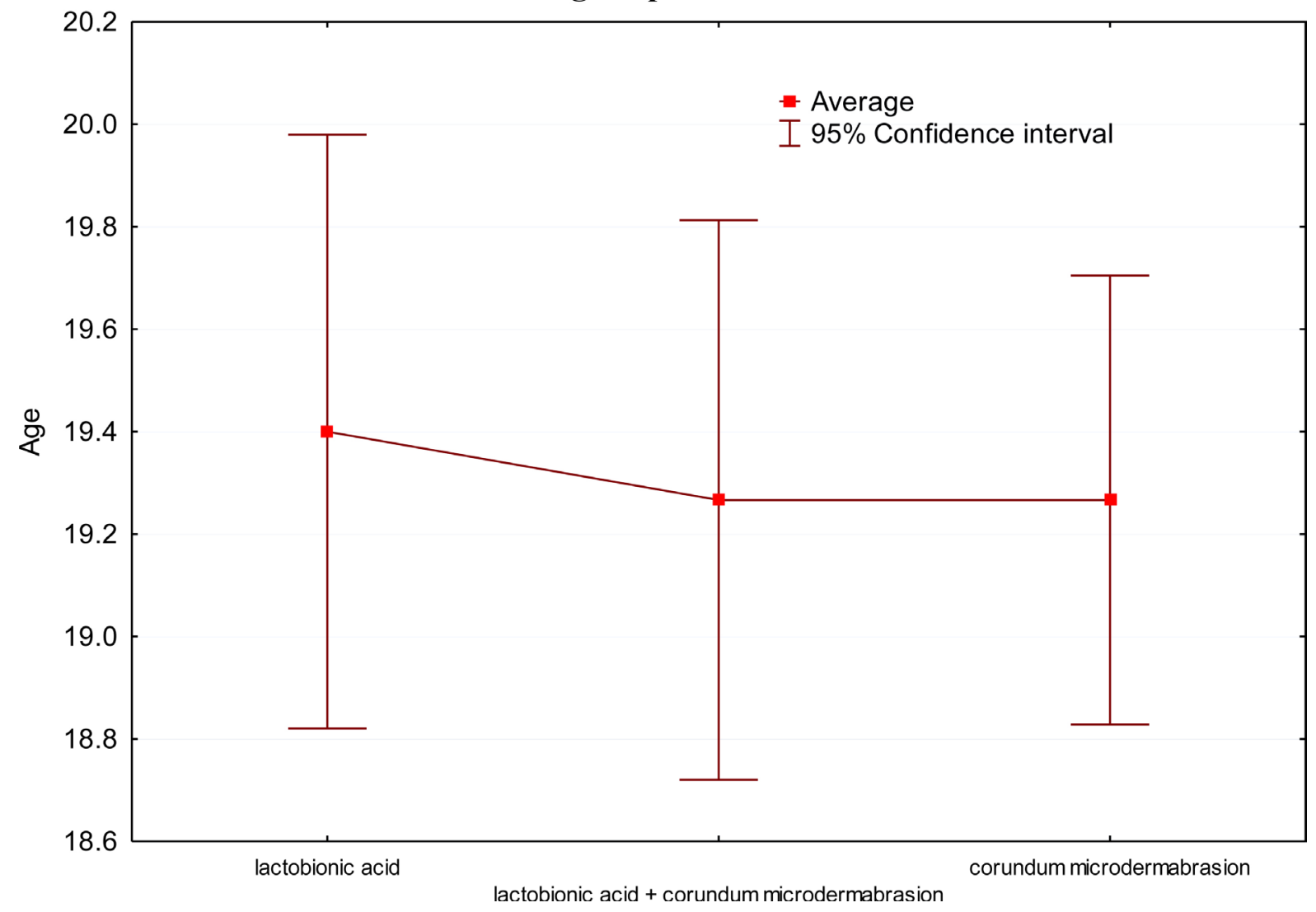

Figure 1. Age of patients in a given treatment group.

surements were conducted in a T zone (a forehead, nose and chin) and in a U zone (a left and right cheek) [4] [9] and the data were analyzed by a computer program and gathered in a database. The measurements (the total of six) were conducted before each session (performed five times in two week intervals) and two weeks after the last session.

Before any treatment, the skin of a patient's face was purified with a gel for acne skin, dried, and left for five hours without the use of any cream. Then, the skin around eyes, nostrils and lips was protected with vaseline. Lactobionic acid (50\%) was applied onto a whole face for 20 minutes, then the face was washed with water, dried and treated with a moisturizing cream with sebum-control properties. Before corundum microdermabrasion, the facial skin was degreased. The exfoliation with aluminum oxide crystals was executed along with the natural orientation of facial muscles. Each move was applied at the pressure of $0.30 \mathrm{bar}(225 \mathrm{mmHg})$ and was repeated three times over ten minutes. After the remaining crystals were removed (with a brush) from the skin, the facial skin was washed with water and a cream containing $5 \%$ of LA and having moisturizing and sebum-control properties was applied. During the combined treatment, first the corundum microdermabrasion was executed along the natural orientation of facial muscles. Each move was applied at the pressure of 0.2 bar (150 $\mathrm{mmHg}$ ) and was repeated three times over ten minutes. Then, 50\% LA was applied for 10 minutes. After that period of time, the facial skin was washed with water and a cream having moisturizing and sebum-control properties was applied. The patients were instructed to use at home the anti-acne washing gel (two times a day) and a sebum-regulating cream, as well as to use sunscreen creams and to avoid direct sunlight.

\subsection{Statistical Methods}

To analyze qualitative properties of a given test group structural indices were calculated. To characterize the average values of quantitative properties an arithmetic mean $(\bar{x})$ and a median $(\mathrm{Me})$ were calculated. Data dispersion was characterized by standard deviation (SD). Also the lowest and the highest values were specified. The generated plots show the mean values and their $95 \%$ confidence intervals. 
Empirical distribution of investigated parameters was analyzed using the Shapiro-Wilk W test. The non-parametric Wilcoxon test for related data was used. The selection of a parametric test also depended on the homogeneity of variance, which was assessed with the Levene test.

To compare within the groups the analyzed parameters in respect to the period of time the treatment was given, the Friedman non-parametric ANOVA test was used, which is an equivalent to the variance test and meets the statistical requirements for this type of analysis.

In all analyses, a significance value $\mathrm{p}<0.05$ was required.

\section{Results}

\subsection{Peeling with Lactobionic Acid}

Before the first session, the average amount of sebum on a forehead was $170.3 \pm 40.1 \mu \mathrm{g} / \mathrm{cm}^{2}$ (median 166.0). Statistically significant differences $(\mathrm{z}=2.8 ; \mathrm{p}=0.005)$ were observed before the third session, when the mean value dropped to $118.3 \pm 33.8 \mu \mathrm{g} / \mathrm{cm}^{2}$ (median 103.0), i.e. to $69.5 \%$ of the initial value. After the last session the mean value further dropped to $99.8 \pm 28.8 \mu \mathrm{g} / \mathrm{cm}^{2}$ (median 95.0), i.e. to $58.6 \%$ of the initial value (Figure 2).

Before the first session, the average amount of sebum on a left cheek was $159.9 \pm 52.5 \mu \mathrm{g} / \mathrm{cm}^{2}$ (median 164.0). Statistically significant differences $(z=2.1 ; p=0.04)$ were observed already before the second session, when the mean value dropped to $132.1 \pm 56.2 \mu \mathrm{g} / \mathrm{cm}^{2}$ (median 117.0), i.e. to $82.7 \%$ of the initial value. After the last session the mean value further dropped to $88.8 \pm 19.0 \mu \mathrm{g} / \mathrm{cm}^{2}$ (median 86.0 ), i.e. to $55.6 \%$ of the initial value (Figure 3).

Before the first session, the average amount of sebum on a right cheek was $157.0 \pm 42.5 \mu \mathrm{g} / \mathrm{cm}^{2}$ (median 171.0). Statistically significant differences $(z=2.9 ; p=0.004)$ were observed before the third session, when the mean value dropped to $98.4 \pm 33.3 \mu \mathrm{g} / \mathrm{cm}^{2}$ (median 91.0), i.e. to $62.7 \%$ of the initial value. After the last session the mean value further dropped to $84.4 \pm 25.9 \mu \mathrm{g} / \mathrm{cm}^{2}$ (median 80.0), i.e. to $53.8 \%$ of the initial value (Figure 4).

Before the first session, the average amount of sebum on the skin of nose was $184.8 \pm 50.8 \mu \mathrm{g} / \mathrm{cm}^{2}$ (median 197.0). Also before the third session statistically significant differences $(z=2.5 ; p=0.02)$ were observed, when

\section{Forehead}

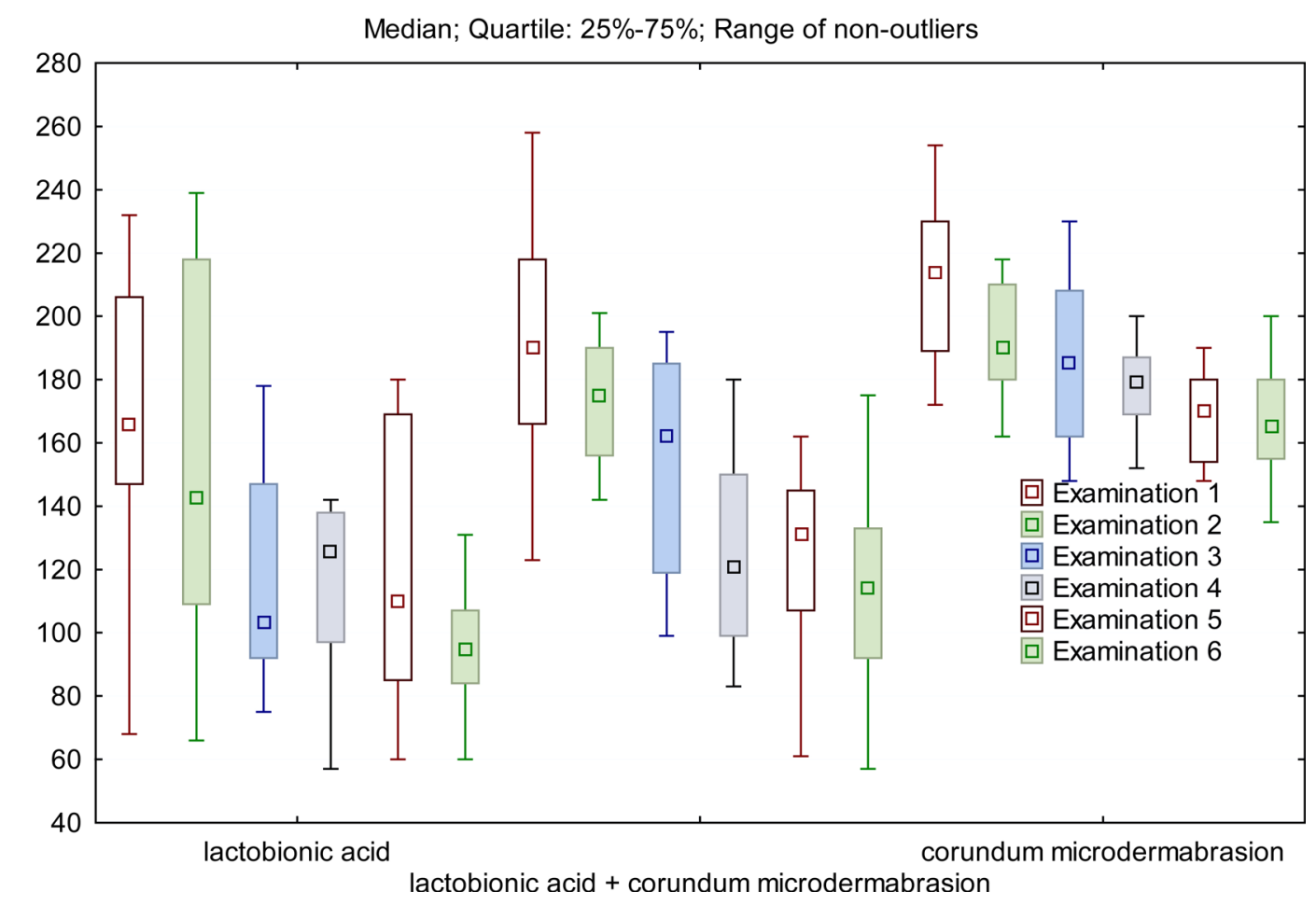

Figure 2. Averaged amounts of sebum (in $\mu \mathrm{g} / \mathrm{cm}^{2}$ ) on a forehead before given sessions of peeling with $50 \%$ LA, the corundum microdermabrasion, or the combined technique. 


\section{Cheek (left)}

Median; Quartile: 25\%-75\%; Range of non-outliers

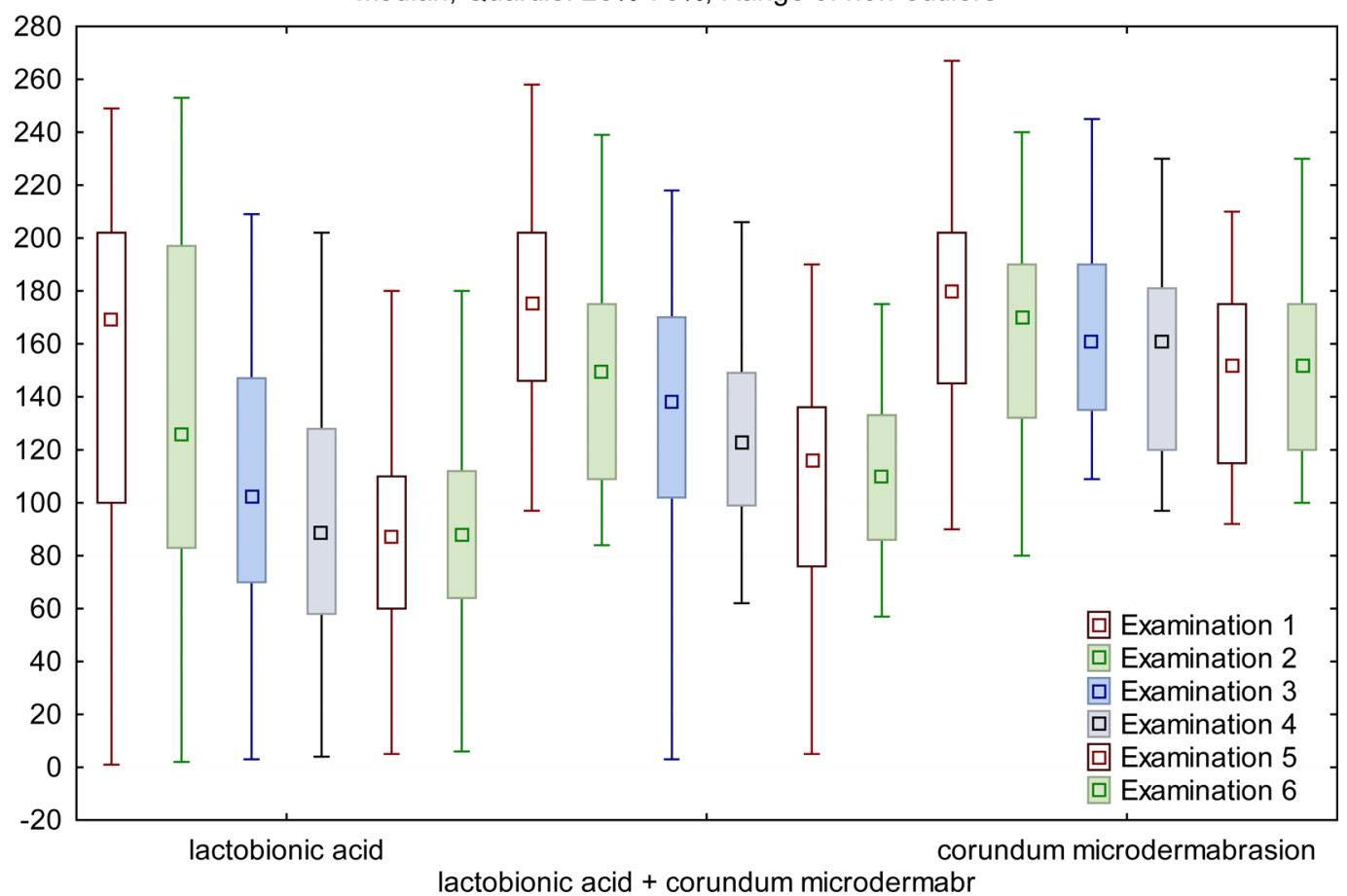

Figure 3. Averaged amounts of sebum (in $\mu \mathrm{g} / \mathrm{cm}^{2}$ ) on a left cheek before given sessions of peeling with $50 \%$ LA, the corundum microdermabrasion, or the combined technique.

\section{Cheek (right)}

Median; Quartile: 25\%-75\%; Range of non-outliers

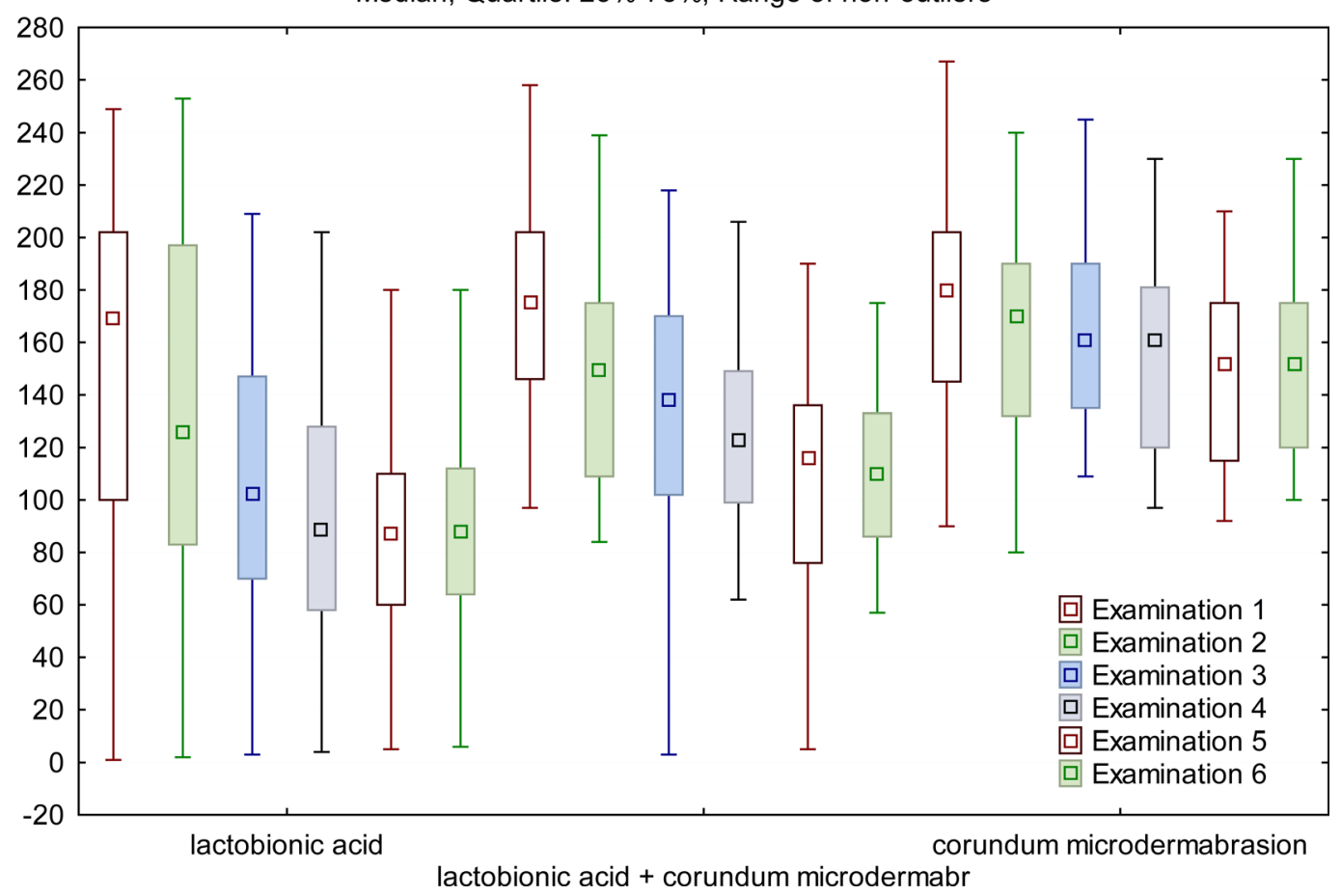

Figure 4. Averaged amounts of sebum (in $\mu \mathrm{g} / \mathrm{cm}^{2}$ ) on a right cheek before given sessions of peeling with $50 \%$ LA, the corundum microdermabrasion, or the combined technique. 
the average amount of sebum was $146.7 \pm 38.1 \mu \mathrm{g} / \mathrm{cm}^{2}$ (median 156.0 ), i.e. $79.4 \%$ of the initial value. After the last session the mean value further dropped to $129.3 \pm 32.8 \mu \mathrm{g} / \mathrm{cm}^{2}$ (median 142.0), i.e. to $69.8 \%$ of the initial value (Figure 5).

The initial average amount of sebum on a chin was $186.5 \pm 35.5 \mu \mathrm{g} / \mathrm{cm}^{2}$ (median 188.0). Statistically significant differences $(\mathrm{z}=2.78 ; \mathrm{p}=0.005)$ were observed before the third session, when the mean value dropped to $131.9 \pm 41.0 \mu \mathrm{g} / \mathrm{cm}^{2}$ (median 123.0), i.e. to $70.8 \%$ of the initial value. After the last session the mean value further dropped to $109.9 \pm 37.5 \mu \mathrm{g} / \mathrm{cm}^{2}$ (median 98.0), i.e. to $52.1 \%$ of the initial value (Figure 6).

\subsection{Corundum Microdermabrasion.}

Before the first session, the average amount of sebum on a forehead was $212.1 \pm 24.6 \mu \mathrm{g} / \mathrm{cm}^{2}$ (median 214.0). Statistically significant differences $(z=3.4 ; p=0.0009)$ were observed before the second session, when the mean value dropped to $193.9 \pm 18.3 \mu \mathrm{g} / \mathrm{cm}^{2}$ (median 190.0), i.e. to $91.4 \%$ of the initial value. After the last session the mean value further dropped to $168.4 \pm 18.6 \mu \mathrm{g} / \mathrm{cm}^{2}$ (median 165.0), i.e. to $79.4 \%$ of the initial value.

The first session brought statistically significant results for a left cheek. The initial average amount of sebum was $161.3 \pm 20.1 \mu \mathrm{g} / \mathrm{cm}^{2}$ (median 158.0). Statistically significant differences $(\mathrm{z}=3.0 ; \mathrm{p}=0.003)$ were observed before the second session, when the mean value dropped to $147.7 \pm 29.3 \mu \mathrm{g} / \mathrm{cm}^{2}$ (median 150.0), i.e. to $91.6 \%$ of the initial value. After the last session the mean value further dropped to $134.1 \pm 21.6 \mu \mathrm{g} / \mathrm{cm}^{2}$ (median 130.0), i.e. to $83.1 \%$ of the initial value. For a right cheek, the initial value was $154.6 \pm 27.4 \mu \mathrm{g} / \mathrm{cm}^{2}$ (median 157.0). Statistically significant differences $(\mathrm{z}=2.1 ; \mathrm{p}=0.003)$ were observed before the third session, when the mean value dropped to $148.2 \pm 21.1 \mu \mathrm{g} / \mathrm{cm}^{2}$ (median 150.0), i.e. to $95.9 \%$ of the initial value. After the last session the mean value further dropped to $131.5 \pm 20.4 \mu \mathrm{g} / \mathrm{cm}^{2}$ (median 130.0 ), i.e. to $85.1 \%$ of the initial value.

Statistically significant differences were observed after the first sessions done on a nose and a chin $(z=3.1, p$ $=0.002$ and $\mathrm{z}=3.2, \mathrm{p}=0.002$, respectively). The corresponding initial average amounts of sebum were $202.8 \pm$ $21.3 \mu \mathrm{g} / \mathrm{cm}^{2}$ (median 200.0) and $208.5 \pm 30.8 \mu \mathrm{g} / \mathrm{cm}^{2}$ (median 201.0). Before the second sessions, the mean values dropped to $191.4 \pm 20.5$ (median 190.0) and $194.3 \pm 20.0 \mu \mathrm{g} / \mathrm{cm}^{2}$ (median 195.0), respectively, (94.4\%

\section{Nose}

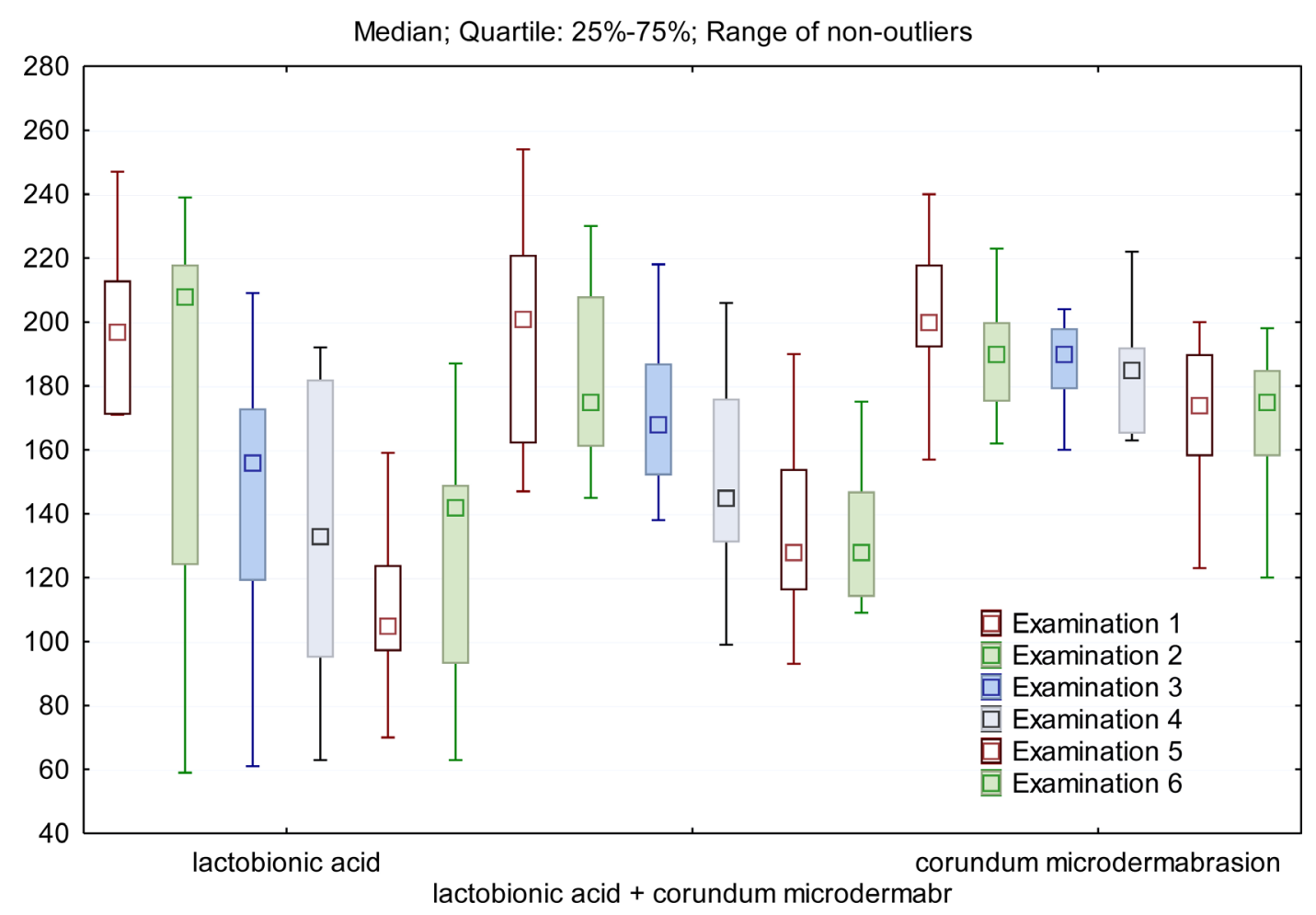

Figure 5. Averaged amounts of sebum (in $\mu \mathrm{g} / \mathrm{cm}^{2}$ ) on a nose before given sessions of peeling with $50 \%$ LA, the corundum microdermabrasion, or the combined technique. 


\section{Chin}

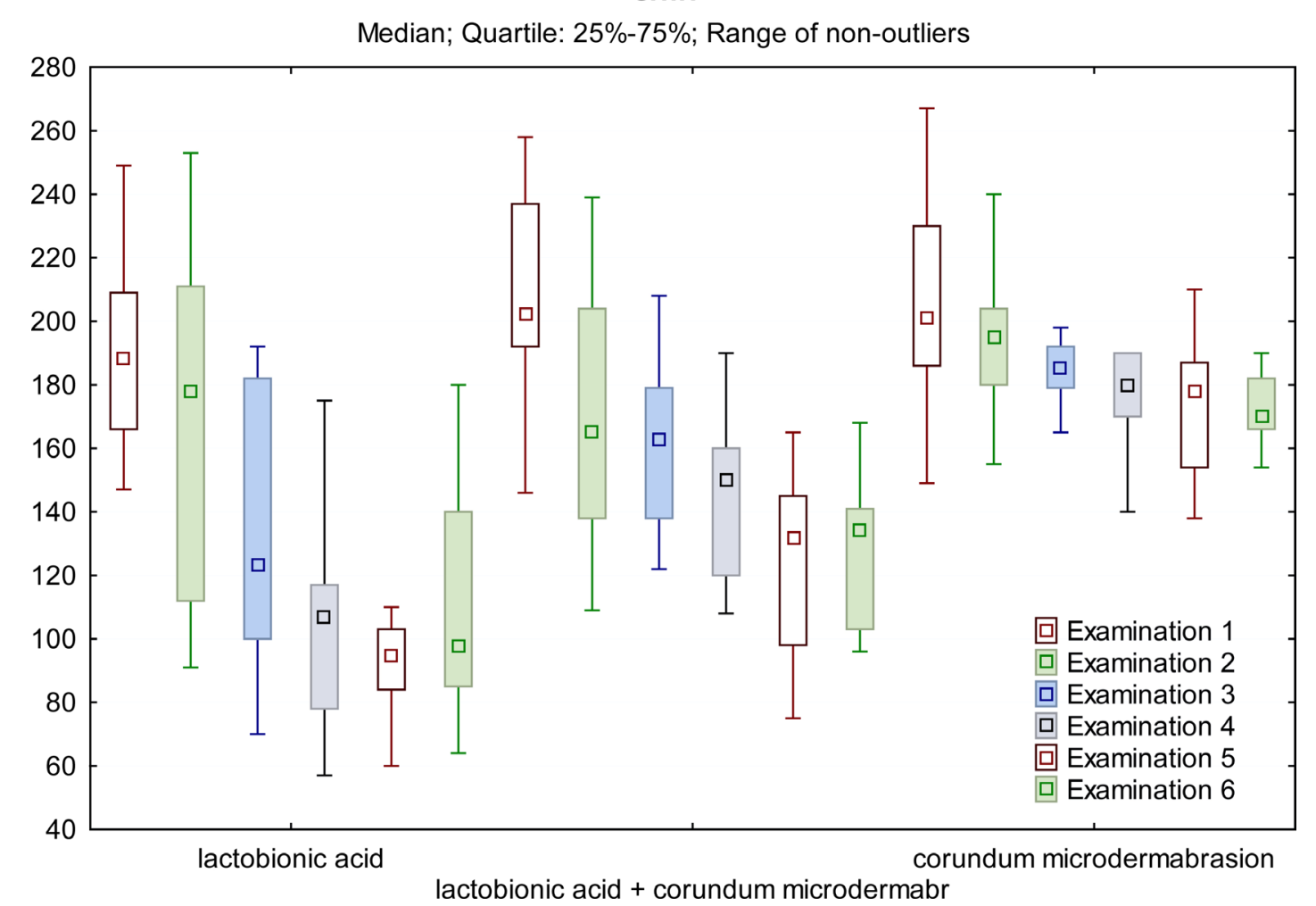

Figure 6. Averaged amounts of sebum (in $\mu \mathrm{g} / \mathrm{cm}^{2}$ ) on a chin before given sessions of peeling with $50 \%$ LA, the corundum microdermabrasion, or the combined technique.

and $93.1 \%$ of the initial value). After the last session, the mean values further dropped to $169.3 \pm 23.0 \mu \mathrm{g} / \mathrm{cm}^{2}$ (median 175.0) and $175.5 \pm 22.6 \mu \mathrm{g} / \mathrm{cm}^{2}$ (median 170.0), respectively, ( $83.5 \%$ and $84.1 \%$ of the initial value).

\subsection{Combined Technique-Corundum Microdermabrasion and Lactobionic Acid}

Before the first session, the average amount of sebum on a forehead was $189.9 \pm 36.3 \mu \mathrm{g} / \mathrm{cm}^{2}$ (median 190.0). Statistically significant differences $(z=2.6 ; p=0.009)$ were observed before the third session, when the average amount of sebum was $152.5 \pm 33.4 \mu \mathrm{g} / \mathrm{cm}^{2}$ (median 162.0), i.e. $80.3 \%$ of the initial value. After the last session the mean value further dropped to $115.1 \pm 29.4 \mu \mathrm{g} / \mathrm{cm}^{2}$ (median 114.0), i.e. to $60.6 \%$ of the initial value.

The combined treatment brought, as expected, virtually identical results to a left and a right cheek. The initial average amounts of sebum were $166.3 \pm 22.5 \mu \mathrm{g} / \mathrm{cm}^{2}$ (median 169.0) and $166.7 \pm 33.6 \mu \mathrm{g} / \mathrm{cm}^{2}$ (median 162.0), respectively. Statistically significant differences $(z=3.2 ; p=0.002$ and $z=2.9, p=0.003)$ were observed before the second sessions, when the average amounts of sebum were $137.7 \pm 25.1 \mu \mathrm{g} / \mathrm{cm}^{2}$ (median 138.0) and $137.4 \pm$ $37.4 \mu \mathrm{g} / \mathrm{cm}^{2}$ (median 136.0). After the last sessions, the corresponding mean values further dropped to $108.4 \pm$ $24.5 \mu \mathrm{g} / \mathrm{cm}^{2}$ (median 109.0) and $108.6 \pm 25.8 \mu \mathrm{g} / \mathrm{cm}^{2}$ (median 107.0), respectively. More distinct results were noticed after the combined treatment was applied to a nose and a chin. The initial average amounts of sebum were $198.1 \pm 32.8 \mu \mathrm{g} / \mathrm{cm}^{2}$ (median 201.0) and $209.5 \pm 33.1 \mu \mathrm{g} / \mathrm{cm}^{2}$ (median 202.0), respectively. Statistically significant differences $(\mathrm{z}=2.4 ; \mathrm{p}=0.02$ and $\mathrm{z}=3.3, \mathrm{p}=0.001)$ were observed before the second sessions, when the average amounts of sebum were $184.3 \pm 26.9 \mu \mathrm{g} / \mathrm{cm}^{2}$ (median 175.0) $(93.0 \%$ of the initial value) and $168.1 \pm$ $39.0 \mu \mathrm{g} / \mathrm{cm}^{2}$ (median 165.0) (80.2\%). After the last sessions, the corresponding mean values further dropped to $131.3 \pm 20.3 \mu \mathrm{g} / \mathrm{cm}^{2}$ (median 128.0) and $128.0 \pm 20.4 \mu \mathrm{g} / \mathrm{cm}^{2}$ (median 134.0), respectively, i.e. to $66.3 \%$ and $61.1 \%$ of the initial value, respectively.

\section{Discussion}

Not many scientific papers deal with the effects of corundum microdermabrasion and chemical peeling on the 
skin lipid layer [10]. Our own results indicate that corundum microdermabrasion, peeling with $50 \%$ LA, and the combined technique, all bring significant decrease in the level of sebum secretion. These effects may result from chemical interaction with the skin lipid layer.

Lactobionic acid is a product of oxidation of a natural disaccharide - lactose. It consists of a carbohydrate D-galactose connected with a D-gluconic acid moiety through an acetal linkage, which can be cleaved enzymatically in vivo. LA is a bionic acids family member consisting of polyhydroxy acids (PHA) carrying a D-galactose unit (Figure 7). Galactose is an endogenous sugar (of a hexose type) used in biosynthesis of e.g. glycosaminoglycans or collagen. D-gluconic acid belongs to a family of polyhydroxy acids, which are known for beneficial effects towards skin. Therefore, D-gluconic acid (or gluconolactone) is often used in cosmetic products. Because of valuable properties of its structural motifs, LA has been successfully implemented into different cosmetic products. It reduces the secretion of sebum and inhibits certain metalloproteinases present in skin matrix and in this way slows down the formation of wrinkles and teleangiectasias. Also its ability to prevent tissue damage associated with hydroxyl radicals (due to the chelation of $\mathrm{Fe}^{2+}$ ) is more and more appreciated.

LA is a hygroscopic substance, which easily forms a gel containing $14 \%(\mathrm{w} / \mathrm{w})$ of water and exerting occlusive properties more intensely than other humectants (eg. glycerol). This is because of the polyhydroxyl structural motif, resembling to a certain extent glycosaminoglycans. Taking into account that the physicochemical parameters of LA (molecular mass $358 \mathrm{~g} / \mathrm{mol}$ and $\mathrm{pKa}=3.8$ ) and its structure are similar to those for glycolic acid [11]-[15], one may expect for LA some exfoliating properties.

The use of typical $\alpha$-hydroxy acids (AHA) usually offers many benefits, but often causes skin irritation. This awful side effect is associated with elevated acidity of AHA, as massive production of hydrogen ion during the dissociation process is harmful to the tissues. Nonetheless, high bioavailability of the active ingredients correlates with low $\mathrm{pH}$, because only undissociated species effectively penetrate the skin and the exfoliation is most efficient with AHA used at $\mathrm{pH}$ lower than their pKa [14] [16]-[18].

The D-galactose unit present in LA makes it more tolerable and less irritating to the skin compared to other
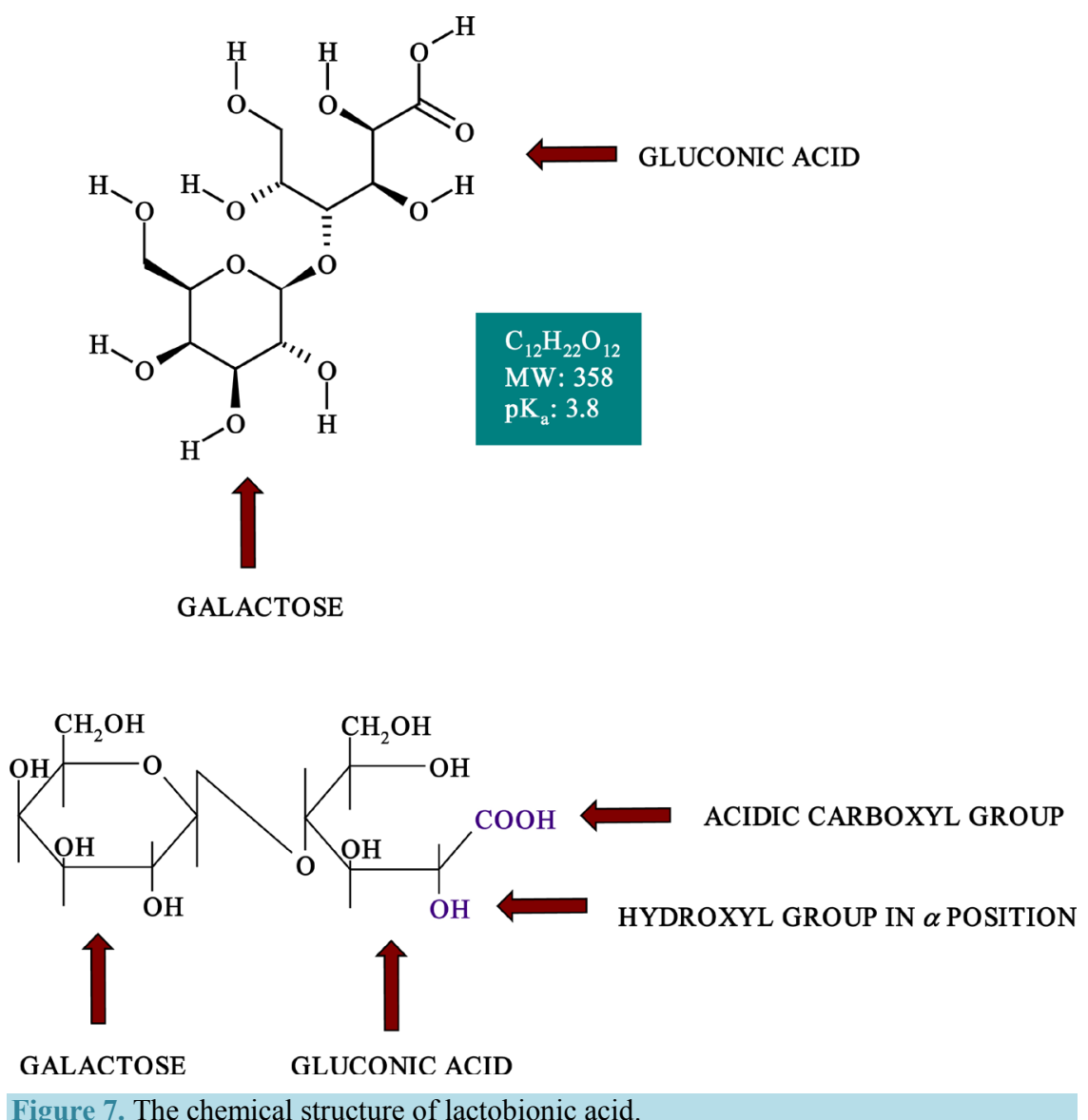
AHA. Also, the dimensions of the LA molecule $\left(885.19 \AA^{3}\right)$, being bigger than those of widely used AHA, slow down penetration through the skin. Thus, LA molecules migrate slowly through the skin layers, so skin irritation is substantially reduced compared to other peeling agents [13].

The most patients suffering from papulopustular acne (of low or medium intensity), peeling with $40 \%-50 \%$ pyruvic acid (for 3 - 4 months, at two weeks intervals) brought significant improvement without apparent side-effects [19]. In other treatment scheme, every two weeks (a total of 6 times) twenty patients with acne vulgaris (of low or medium intensity) had 30\% glycolic acid (an $\alpha$-hydroxy acid) applied on a one half of the face, and 30\% salicylic acid (an aromatic hydroxy acid) on the other [20]. Although the salicylic was expected to be more effective (because of known higher lipophilicity), no difference was noted and both peeling agents worked with similar efficacy. Changes in the sebum secretion were not analyzed [6].

Determination of the sebum level (monitored with a sebumeter) in acne patients after chemical peeling with $30 \%$ glycolic acid and Jassner solution showed virtually no changes, although reduced keratinization led to the unblocking of sebaceous glands and improvement of the skin appearance [21].

Within corundum microdermabrasion the outer layers of epidermis are removed, and this treatment is considered a mild and non-invasive way for speeding up the exfoliation process [22]-[24]. Aluminum oxide $\left(\mathrm{Al}_{2} \mathrm{O}_{3}\right.$, corundum) is a natural compound of high purity, and, importantly, is not harmful to the organism. It has good abrasion ability, does not penetrate the skin, and these features together with its antibacterial properties make the corundum microdermabrasion a useful method supporting the anti-acne treatment [25]-[27]. Also, the corundum microdermabrasion facilitates the penetration of skin by active ingredients due to the abrasion of stratum corneum [28]. Repeated microdermabrasion treatments stimulate regeneration and improve the elasticity of the skin. These effects occur not only within the epidermis, which after the removal of dead layers becomes smoother, but also within the skin matrix, where biosynthesis of collagen and elastin gets stimulated [29]. Most likely, these positive changes result from the stimulation of the epidermis cell proliferation, and from the controlled skin irritation leading to the enhancement of biosynthesis of pro-inflammatory cytokines, transcription enzymes, and eventual skin regeneration [29]. Microdermabrasion reduces seborrhea in fatty skin, however, there is limited amount of data available on the influence of this treatment on sebum secretion, skin hydration, $\mathrm{pH}$, and transepidermal water loss (TEWL), while the available results are inconsistent [10] [23]-[27] [29] [30].

Treatments consisting of the peeling with $50 \%$ lactobionic acid, corundum microdermabrasion, or the combined technique (all provided in five sessions, with two-week intervals) were well tolerated and brought statistically significant decrease in the level of sebum secretion. The corundum microdermabrasion and the combined method resulted also in temporary erythema, which was not detected after the use of $50 \%$ LA, perhaps because of its healing and hydrating properties.

Chemabrasion with 50\% LA reduced the skin lipid layer faster than the combined method, with the corundum microdermabrasion being the least effective. To a certain extent the high efficacy of the chemabrasion may result from a relatively long time of the single treatment (20 minutes), compared to the combined technique (10 minutes). However, this rank of efficacy predominantly results from the fact that, depending on the degree of pressure reduction, treatment time and the size of corundum particles, microdermabrasion may strongly reduce the epidermal barrier [31]. While these changes may bring some clinical improvement and may reduce keratosis pilaris, they may also too much accelerate the penetration of LA (or other active ingredients) through the skin [28].

As mentioned earlier, the D-galactose unit present in LA makes it more tolerable and less irritating to the skin, compared to other AHA, even at high concentration and with simultaneous corundum microdermabrasion. To achieve high bioavailability of LA, the $\mathrm{pH}$ of the solution was set well below the $\mathrm{pKa}$ value $(\mathrm{pH}=1.65 ; \mathrm{pKa}$ $=3.8$ ). This $\mathrm{pH}$ pushed the LA dissociation reaction in the direction of undissociated species, which exert better exfoliating properties and offer high safety.

\section{Acknowledgements}

The study was supported by the statutory research activity no. 503/3-066-02/503-01 and 503/3-066-01/503-31-001.

\section{References}

[1] Cordain, L., Lindeberg, S., Hurtado, M., et al. (2002) Acne Vulgaris: A Disease of Western Civilization. Archives of Dermatology, 138, 1584-1590. http://dx.doi.org/10.1001/archderm.138.12.1584 
[2] Nguyen, T.H. and Rooney, J.A. (2000) Trichloroacetic Acid Peels. Dermatologic Therapy, 2, 173-182. http://dx.doi.org/10.1046/j.1529-8019.2000.00020.x

[3] Urbanowski, S. (1996) Superficial, Mmedium and Deep Peels. Postepy Dermatologii, 13, 239-245.

[4] Youn, S.W., Na, J.I., Choi, S.Y., et al. (2005) Regional and Seasonal Variations in Facial Sebum Secretions: A Proposal for the Definition of Combination Skin Type. Skin Research and Technology, 11, 189-195. http://dx.doi.org/10.1111/j.1600-0846.2005.00119.x

[5] Burke, B.M. and Cunliffe, W.J. (1984) The Assessment of Acne Vulgaris-The Leeds Technique. British Journal of Dermatology, 3, 83-92. http://dx.doi.org/10.1111/j.1365-2133.1984.tb04020.x

[6] Marczyk, B., Budzisz, E. and Rotsztejn, H. (2011) Sebum Secretion and Its Measurements in Patients with Acne Vulgaris in the Light of Present Knowledge. Dermatologic Clinics, 13, 263-266.

[7] Wójcik, A., Budzisz, E. and Rotsztejn, H. (2011) Skin Surface Lipids and Their Measurements. Postepy Dermatologii $i$ Allergologii, 6, 498-505.

[8] Dikstein, S., Zlotogorski, A., Avriel, E., et al. (1987) Comparison of the Sebumeter and the Lipometer. Bioengineering of the Skin, 3, 197-207.

[9] Pagnoni, A., Kligman, A.M., Gammal, S.E.L., et al. (1994) Determination of Density of Follicles on Various Regions of the Face by Cyanoacrylate Biopsy: Correlation with Sebum Output. British Journal of Dermatology, 131, 862-865. http://dx.doi.org/10.1111/j.1365-2133.1994.tb08590.x

[10] Lew, B.L., Cho, Y. and Lee, M.H. (2006) Effect of Serial Microdermabrasion on the Ceramide Level in the Stratum Corneum. Dermatologic Surgery, 32, 376-379.

[11] Edison, B.L., Green, B.A., Wildnauer, R.H., et al. (2004) A Polyhydroxy Acid Skin Care Regimen Provides Antiaging Effects Comparable to an Alpha-Hydroxyacid Regimen. Cutis, 73, 14-17.

[12] Green, B.A., Edison, B.L. and Sigler, M.L. (2008) Antiaging Effects of Topical Lactobionic Acid: Results of a Controlled Usage Study. Journal of Cosmetic Dermatology, 21, 76-82.

[13] Draelos, Z.D., Green, B.A. and Edison, B.L. (2006) An Evaluation of $\alpha$ Polyhydroxy Acid Skin Care Regimen in Combination with Azelaic Acid 15\% Gel in Rosacea Patients. Journal of Cosmetic Dermatology, 5, 23-29. http://dx.doi.org/10.1111/j.1473-2165.2006.00219.x

[14] Green, B.A., Yu, R.J. and Van Scott, E.J. (2009) Clinical and Cosmeceutical Uses of Hydroxyacids. Clinics in Dermatology, 27, 495-501. http://dx.doi.org/10.1016/i.clindermatol.2009.06.023

[15] Tasic-Kostov, M., Pavlovic, D., Lukic, M., et al. (2012) Lactobionic Acid as Antioxidant and Moisturizing Active in Alkyl Polyglucoside-Based Topical Emulsions: The Colloidal Structure, Stability and Efficacy Evaluation. International Journal of Cosmetic Science, 34, 424-434. http://dx.doi.org/10.1111/j.1468-2494.2012.00732.x

[16] Marczyk, B., Mucha, P. and Rotsztejn, H. (2012) Effect of Chemical Peelings the Most Often Used in Acne Vulgaris. Clinical Dermatology, 14, 183-187.

[17] Marczyk, B., Mucha, P., Budzisz, E. and Rotsztejn, H. (2014) Comparative Study of the Effect of 50\% Pyruvic and 30\% Salicylic Peels on Skin Lipid film in Patients with Acne Vulgaris. Journal of Cosmetic Dermatology, 13, 15-21. http://dx.doi.org/10.1111/jocd.12050

[18] Ghersetich, I., Brazzini, B., Peris, K., et al. (2004) Pyruvic Acid Peels for the Treatment of Photoaging. Dermatologic Surgery, 30, 32-36.

[19] Cotellessa, C., Manunta, T. and Ghersetich, I. (2004) The Use of Pyruvic Acid in the Treatment of Acne. Journal of the European Academy of Dermatology and Venereology, 18, 275-278. http://dx.doi.org/10.1111/j.1468-3083.2004.00759.x

[20] Kessler, E., Flanagan, K., Chia, C., Cynthia, R. and Dee, A.G. (2008) Comparison of $\alpha$ and $\beta$ Hydroxy Acid Chemical Peels in the Treatment of Mild to Moderately Severe Facial Acne Vulgaris. Dermatologic Surgery, 34, 45-51. http://dx.doi.org/10.1097/00042728-200801000-00008

[21] Lee, S.M., Huh, C.H., Park, K.C. and Youn, S.W. (2006) Effects of Repetitive Superficial Peels on Facial Sebum Secretion in Acne Patients. Journal of the European Academy of Dermatology and Venereology, 20, 964-968. http://dx.doi.org/10.1111/j.1468-3083.2006.01695.x

[22] Shim, E.K., Barnette, D., Hughes, K. and Greenway, H.T. (2001) Microdermabrasion: A Clinical and Histopathologic Study. Dermatologic Surgery, 27, 524-530. http://dx.doi.org/10.1097/00042728-200106000-00004

[23] Alkhawam, L. and Alam, M. (2009) Dermabrasion and Microdermabrasion. Facial Plastic Surgery, 25, 301-310. http://dx.doi.org/10.1055/s-0029-1243078

[24] Bhalla, M. and Thami, G.P. (2006) Microdermabrasion: Reappraisal and Brief Review of Literature. Dermatologic Surgery, 32, 809-814. http://dx.doi.org/10.1097/00042728-200606000-00009 
[25] Savardekar, P. (2007) Microdermabrasion. Indian Journal of Dermatology Venereology \& Leprology, 73, $277-279$. http://dx.doi.org/10.4103/0378-6323.33650

[26] Nguyen, T. (2014) Dermatology Procedures: Microdermabrasion and Chemical Peels. FP Essentials, 426, 16-23.

[27] Fernandes, M., Pinheiro, N.M., Crema, V.O. and Mendonça, A.C. (2014) Effects of Microdermabrasion on Skin Rejuvenation. Journal of Cosmetic \& Laser Therapy, 16, 26-31. http://dx.doi.org/10.3109/14764172.2013.854120

[28] Gill, H.S., Andrews, S.N., Sakthivel, S.K., et al. (2009) Selective Removal of Stratum Corneum by Microdermabrasion to Increase Skin Permeability. European Journal of Pharmaceutical Sciences, 38, 95-103. http://dx.doi.org/10.1016/j.ejps.2009.06.004

[29] Karimpour, D.J., Kang, S., Johnson, T.M., et al. (2005) Microdermabrasion: A Molecular Analysis Following a Single Treatment. Journal of the American Academy of Dermatology, 52, 215-223. http://dx.doi.org/10.1016/j.jaad.2004.10.008

[30] Davari, P., Gorouhi, F., Jafarian, S., et al. (2008) The Effects of Different Intervals of Microdermabrasion Sessions on Skin Biophysical Parameters: A Randomized, Assessor-Blind, Within-Patient Trial. Iranian Journal of Dermatology, 11, 49-54.

[31] Karimipour, D.J., Karimipour, G. and Orringer, J.S. (2010) Microdermabrasion: An Evidence-Based Review. Plastic and Reconstructive Surgery, 125, 372-377. http://dx.doi.org/10.1097/PRS.0b013e3181c2a583

\section{Submit or recommend next manuscript to SCIRP and we will provide best service for you:}

Accepting pre-submission inquiries through Email, Facebook, LinkedIn, Twitter, etc.

A wide selection of journals (inclusive of 9 subjects, more than 200 journals)

Providing 24-hour high-quality service

User-friendly online submission system

Fair and swift peer-review system

Efficient typesetting and proofreading procedure

Display of the result of downloads and visits, as well as the number of cited articles

Maximum dissemination of your research work

Submit your manuscript at: http://papersubmission.scirp.org/ 